\title{
Histidine and histidine dimer as green inhibitors for carbon steel in 3wt\% sodium chloride solution; Electrochemical, XPS and Quantum chemical calculation studies
}

\author{
Liyun Zhang ${ }^{1,2}$, Shihong Zhang ${ }^{2}, \mathrm{Yi} \mathrm{He}^{1,2,3, *}$, Ranran Yang ${ }^{2}$, Lan $\mathrm{Ma}^{2}$, Yunqing Xia ${ }^{2}, \mathrm{Ze} \mathrm{He} e^{2, *}$ \\ ${ }^{1}$ State Key Lab of Oil and Gas Reservoir Geology and Exploitation, Southwest Petroleum University, \\ 8 Xindu Avenue, Chengdu, Sichuan 610500, P R of China \\ ${ }^{2}$ School of Chemistry and Chemical Engineering, Southwest Petroleum University, 8 Xindu Avenue, \\ Chengdu, Sichuan 610500, P R of China \\ ${ }^{3}$ Oil \& Gas Field Applied Chemistry Key Laboratory of Sichuan Province, Chengdu, 610500, China \\ *E-mail: heyi@swpu.edu.cn, heze1313@hotmail.com
}

doi: $10.20964 / 2018.02 .76$

Received: 28 October 2017 / Accepted: 14 December 2017 / Published: 28 December 2017

\begin{abstract}
Histidine (ethyl-2-amino-3-(1H-imidazol-2-yl) propanoate), a raw material, was used to synthesize a new green histidine dimer (2-(2-amino-3-(1H-imidazol-2-yl)propanamido)-3-(1H-imidazol-2yl)propanoic acid) inhibitor. The corrosion inhibition properties of histidine and the histidine dimer for $\mathrm{N} 80$ steel were explored in $3 \mathrm{wt} \% \mathrm{NaCl}$ solution through weight loss experiments and electrochemistry experiments (including potentiodynamic polarization tests and electrochemical impedance spectroscopy (EIS)). The surface morphology and elemental composition of corroded N80 steels were analysed by scanning electronic microscopy (SEM), energy dispersive spectroscopy (EDS) and X-ray photoelectron spectroscopy (XPS). Weight loss experiments showed that the histidine dimer has better inhibitory performance than histidine. When the dosages of histidine and the histidine dimer reached $250 \mathrm{mg} / \mathrm{L}$, the inhibition efficiency reached maximum values of $86 \%$ and $94 \%$, respectively. In addition, the results of Scanning Electron Microscopy (SEM) and X-ray photoelectron spectroscopy (XPS) further confirmed that histidine and the histidine dimer can form a protective layer on the surface of N80 steel. The inhibition mechanism and molecular structure of histidine and the histidine dimer were analysed by quantum chemical calculation methods, and the results showed that the better inhibition efficiency of the histidine dimer may be due to the increase of adsorption sites on the histidine dimer compared with histidine, which facilitates adsorption on the surface of N80 steel. Moreover, the examination of adsorption properties showed that the adsorption behaviour of histidine and the histidine dimer on N80 steel followed the Langmuir adsorption isotherm model.
\end{abstract}

Keywords: Histidine dimer, green corrosion inhibitor, carbon steel, chloride sodium. 


\section{FULL TEXT}

(C) 2018 The Authors. Published by ESG (www.electrochemsci.org). This article is an open access article distributed under the terms and conditions of the Creative Commons Attribution license (http://creativecommons.org/licenses/by/4.0/). 